\title{
Risk Factors for Coronary Heart Disease and Family Medicine - What Can be Done?
}

\author{
Dalibor Mihajlović, ${ }^{1,2}$ Biljana Mihajlović,, ${ }^{3}$ Nevena Todorović, ${ }^{3}$ Žana M \\ Maksimović2, 4
}

\section{Abstract}

Background / Aim: More people die each year due to cardiovascular diseases (CVDs) than from any other cause. The most common cause of ischaemic heart diseases (IHD) is atherosclerosis of the coronary arteries. Risk factors for the development of coronary heart disease (CHD) can be preventable and non-preventable. The aim of the study was to determine the frequency of individual risk factors in patients with CHD.

Methods: Retrospective analysis included patients with diagnoses of stable angina pectoris (AP), unstable angina pectoris and myocardial infarction - acute coronary syndrome (ACS) and ischaemic cardiomyopathy (iCMP). The prevalence of the following risk factors for IHD was analysed: hypertension, diabetes, obesity, cholesterol, smoking, family history, age and sex. Data were taken from the Register of Patients with Chronic Diseases and Risk Factors and electronic patient records.

Results: Of the total number of respondents older than 18, $4.95 \%$ had CHD. Of the 178 patients with IHD, 70 (39.3\%) patients had AP, 60 (33.7\%) patients had ACS and 48 (27.0\%) patients had iCMP. Positive family history had $63.5 \%$ of patients, $72 \%$ were older than $66,24.1 \%$ were smokers and $74.2 \%$ of patients had elevated blood cholesterol levels. Diabetes mellitus affected $29.2 \%$ of patients, hypertension $88.8 \%$, and BMI $\geq 25 \mathrm{~kg} / \mathrm{m}^{2}$ had $70.8 \%$ of patients.

Of the total number of patients with ACS, $68.3 \%$ were men, while higher percentage of women suffered from AP $(62.9 \%)(p=0.002)$. In the age below 65 , CHD was more common in men $(p=0.007)$. Cholesterol was elevated more often in patients with AP than iCMP ( $\mathrm{p}=0.001)$. Patients with ACS were more likely to have diabetes mellitus compared to patients with AP and iCMP $(p=0.010)$.

Conclusion: The prevalence of preventable risk factors is alarmingly high. of particular importance is the timely detection and treatment of risk factors by family physicians and strengthening the personal responsibility of each individual in choosing their lifestyle and active involvement in the therapeutic process.

Key words: Ischaemic heart disease; Diabetes mellitus; Hypertension; Obesity; Dyslipidaemia; Smoking; Physical inactivity.
1) Emergency Department, Primary Healthcare Centre Banja Luka, Banja Luka, the Republic of Srpska, Bosnia and Herzegovina.

(2) Centre for Biomedical Research, Faculty of Medicine, University of Banja Luka, Banja Luka, the Republic of Srpska, Bosnia and Herzegovina.

(3) Primary Healthcare Centre Banja Luka, Banja Luka, the Republic of Srpska, Bosnia and Herzegovina.

(4) Emergency Department, Primary Healthcare Centre Modriča, Modriča, the Republic of Srpska, Bosnia and Herzegovina.

Correspondence:

DALIBOR MIHAJLOVIĆ

E: mihajlovic73@yahoo.com

\section{ARTICLE INFO}

Received: 16 October 2021 Revision received: 6 December 2021 Accepted: 7 December 2021

\section{Introduction}

Ischaemic heart disease (IHD) occurs when the heart muscle's need for blood is greater than its ability to supply it. ${ }^{1}$ It occurs in various diseases and conditions in which the need of the myocardium is tampered and/or the blood supply is reduced due to various clinical features. The symp-

Copyright $\odot 2021$ Mihajlovic et al. This is an open access article distributed under the Creative Commons Attribution License (CC BY), which permits unrestricted use, distribution, and reproduction in any medium, provided the original work is properly cited. This article should be cited as follows: Mihajlović D, Mihajlović B, Todorović N, Maksimović ŽM. Risk factors for coronary heart disease and family medicine - what can be done? Scr Med 2021 Sep;52(4):258-65. 
tom of ischaemic myocardium is pain (lat. Angere - choke). ${ }^{2}$

The diagnosis of IHD in generic terms refers to all diseases that lead to myocardial ischaemia, including non-atherosclerotic diseases of the coronary arteries. As atherosclerosis is by far the most common cause of IHD today (in more than $90 \%$ of cases), the diagnosis of IHD in specific terms is used in everyday practice to describe atherosclerotic coronary artery disease. The term coronary heart disease (CHD) is often used for the same diagnoses as IHD in specific terms. ${ }^{3}$

More people die each year due to cardiovascular disease (CVD) than from any other cause. Around 17.7 million people died of CVD in 2016, representing $31 \%$ of all deaths. Of those deaths, about 7.4 million died of CHD and 6.7 million died of stroke. $^{4}$

In Europe, CVDs are responsible for just over 4 million deaths a year, or $47 \%$ of all deaths. ${ }^{5}$ Slightly less than half of CVD deaths are caused by IHD. ${ }^{6,7}$ CVDs are more common in men than in women, but this difference in frequency between the sexes is statistically balanced at the age above $70 .{ }^{8}$

The most common cause of IHD is atherosclerosis of the coronary arteries. Atherosclerosis leads to mechanical - fixed narrowing of the coronary artery, but at the same time it is the basis for the occurrence of dynamic narrowing or spasm of the coronary artery (extremely strong pathological vasoconstriction), which occurs due to endothelial dysfunction. Mechanical and dynamic coronary artery stenosis reduce blood flow in segments of the myocardium supplied by a narrowed coronary artery. ${ }^{9}$ Rare forms of IHD occur when coronary arteries are not altered by an atherosclerotic process but ischaemia is due to some other cause (aortic valve disease, hypertrophic cardiomyopathy, congenital anomalies of coronary circulation). ${ }^{9}$ Atherosclerotic altered coronary arteries lose their normal vasodilatory reserve, already in the early stages of the disease, before the onset of significant narrowing, which is why the coronary flow cannot be adequately increased when myocardial oxygen demand increases. $^{2}$

Risk factors that contribute to the development of atherosclerosis and CHD can be variable and invariable. The main variable (and preventable) risk factors include: hypertension, obesity, dyslipidaemia, diabetes mellitus, smoking and physical inactivity and the invariable risk factors include family history, sex and age. ${ }^{8,10}$ The risk of developing CHD increases progressively with high blood pressure. ${ }^{11}$ Central type of obesity is more reliable risk marker for CHD than general type of obesity, determined by body mass index. ${ }^{12}$ Weight loss has a good impact on blood pressure, dyslipidaemia and glucose metabolism. The risk increases with an increase in total cholesterol and low-density lipoprotein (LDL) cholesterol and with a decrease in high-density lipoprotein (HDL) cholesterol levels. ${ }^{13}$ Progression of CHD can be prevented by good glycoregulation. ${ }^{14}$ Preferably, the HbA1c values should be 6.5-6.9\%. The risk of developing CHD is reduced by $50 \%$ one year after smoking cessation. ${ }^{15}$ Individually tailored physical activity should be an integral part of everyday life. ${ }^{16}$

If CHD occurred in male relatives before the age of 55 and in females before the age of 65 , the person is considered to have a positive family history of CHD. CHD is more common in men up to 75 years of age. ${ }^{17}$ The risk increases with age. ${ }^{18}$

CHD can be clinically manifested as angina pectoris (AP), acute myocardial infarction (AMI), mute ischaemia, cardiac arrhythmia, sudden cardiac death, heart failure due to ischaemic cardiomyopathy (iCMP). Acute coronary syndrome is one of the most common and dramatic manifestations of ischaemic heart disease. ${ }^{19}$ The term acute coronary syndrome encompasses three different entities of acute manifestation of coronary heart disease: Unstable angina pectoris (UAP), Non-ST elevation myocardial infarction (NSTEMI) and ST elevation myocardial infarction (STEMI). ${ }^{8}, 20$ Non-ST-elevation myocardial infarction and unstable angina are commonly referred to as nonSTEMI acute coronary syndromes. ${ }^{21}$

The aim of the study was to analyse the prevalence and importance of risk factors in CHD patients: hypertension, diabetes, obesity, cholesterol, smoking, family history, age and sex.

\section{Methods}

This research was a retrospective cross-sectional study. Data from two family medicine teams in the Primary Healthcare Centre in Banja Luka 
were analysed. By using data from the Register of Chronic Non-Communicable Diseases (CVD Registry) of selected teams, patients with diagnoses of stable and unstable AP, AMI and iCMP were identified.

Data on the presence of individual risk factors were taken from electronic patient records. The following parameters were recorded: hypertension, diabetes, obesity, cholesterol, smoking, positive family history, age and sex. For obesity, the value of the Body Mass Index (BMI) $\geq 25.0 \mathrm{~kg} / \mathrm{m}^{2}$ was taken as a risk factor. ${ }^{22} \mathrm{~A}$ value higher than $5.2 \mathrm{mmol} / \mathrm{L}$ was taken as elevated cholesterol. Patients were classified into age groups as follows: $18-45$, 46-55, 56-65 years and fourth group older than 65 .

Data were analysed in IBM SPSS Statistic 18.0. Descriptive analysis in the form of frequencies and percentages was used to review the sample and individual variables. Category data were compared using the Chi-square test. Statistical significance was set at $\mathrm{p}<0.05$.

\section{Results}

The total number of registered patients older than 18 in the two selected family medicine teams was 3634. The study analysed a total of 178 patients (4.95\% of the total number of patients older than 18) with diagnoses of stable and unstable AP, myocardial infarction and iCMP.

Of the 178 patients, 92 (51.7\%) were male and 86 $(48.3 \%)$ were female (Table 1$)$. Only one patient $(0.6 \%)$ was younger than 45 . There were $9(5.1 \%)$ patients in the age between 46-55. A significantly higher number of patients, 40 of them $(22.5 \%)$ was in the age between 56-65 and the largest number of patients was older than 66,128 or $72 \%$ (Table 1 ).

Table 1: Gender and age distribution of patients with ischaemic heart disease

\begin{tabular}{ccc}
\hline Parameter & N & $\%$ \\
\hline Gender & & \\
\hline Male & 92 & 51.69 \\
\hline Female & 86 & 48.31 \\
\hline Age (Years) & & \\
\hline $18-45$ & 1 & 0.56 \\
\hline $46-55$ & 9 & 5.06 \\
\hline $56-65$ & 40 & 22.47 \\
\hline$\geq 66$ & 128 & 71.91 \\
\hline Total & 178 & 100.00 \\
\hline
\end{tabular}

Out of the total number of patients, 113 patients had a positive family history (63.5 \%), 43 patients were smokers (24.1\%), and 132 patients (74.2\%) had elevated blood cholesterol values. Diabetes mellitus affected 52 patients (29.2\%), hypertension 158 (88.8\%) patients and there were $126(70.8 \%)$ overweight/obese patients (Table 2).

Table 2: Recorded risk factors in patients with ischaemic heart disease

\begin{tabular}{ccc}
\hline Risk factors & N & $\%$ \\
\hline Family history & & \\
\hline Positive & 113 & 63.48 \\
\hline Negative & 65 & 36.52 \\
\hline Tobacco use & 43 & 24.16 \\
\hline Yes & 135 & 75.84 \\
\hline No & & \\
\hline Chol (mmol/L) & 132 & 74.16 \\
\hline$<5.2$ & 46 & 25.84 \\
\hline$\geq 5.2$ & & \\
\hline Diabetes mellitus & 52 & 29.21 \\
\hline Yes & 126 & 70.79 \\
\hline No & & \\
\hline BMl (kg/m & & \\
\hline$<25$ & 126 & 70.79 \\
\hline$\geq 25$ & 52 & 29.21 \\
\hline Hypertension & & \\
\hline Yes & 158 & 88.76 \\
\hline No & 20 & 11.24 \\
\hline Total & 178 & 100.00 \\
\hline
\end{tabular}

Considering the type of IHD, 70 (39.3\%) patients had AP, 60 (33.7\%) patients had ACS, and 48 $(27.0 \%)$ patients had iCMP (Figure 1).

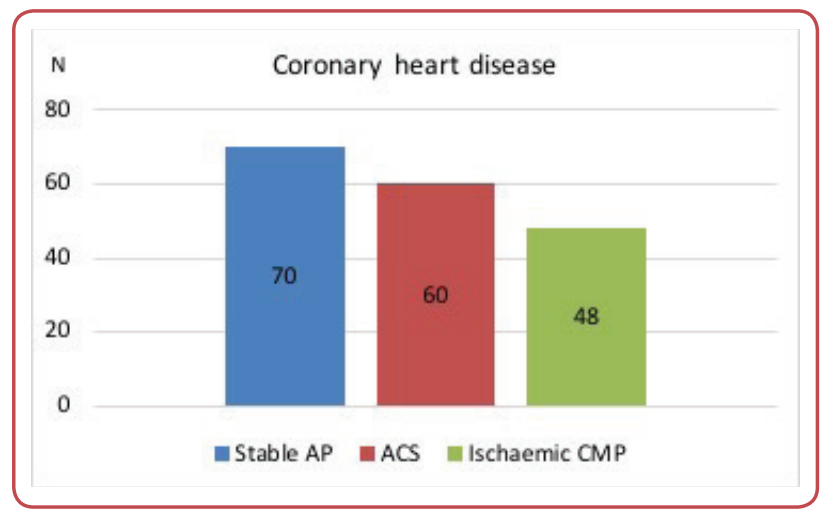

Figure 1: Distribution of certain types of ischaemic heart disease in the examined sample

${ }^{*} A P$ : angina pectoris; ACS: acute coronary syndrome; CMP: cardiomyopathy;

A significant difference was found between certain types of CHD and the sex of the patient $\left(\chi^{2}=12.59, \mathrm{p}\right.$ $=0.002$ ). Of the total number of patients with ACS, $68.3 \%$ were men, while in the case of AP, there was a higher percentage of women (62.9\%). 


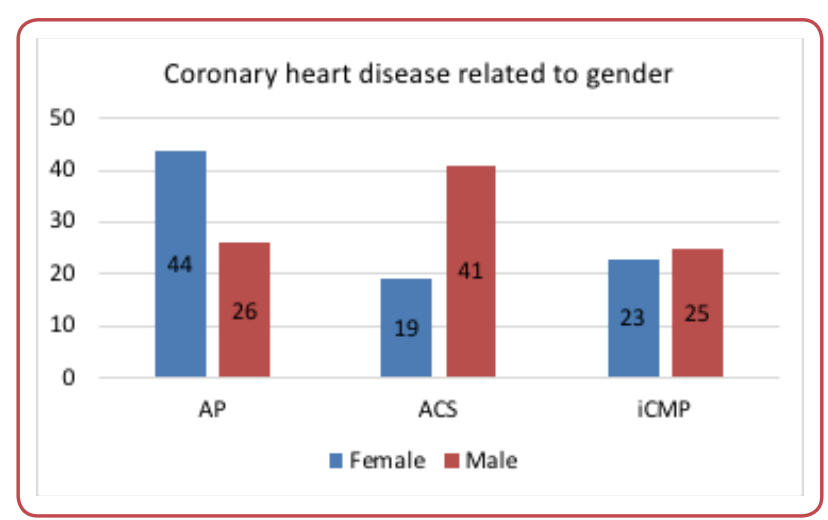

Figure 2: Distribution of the type of ischaemic heart disease by sex ${ }^{\star} A P$ : angina pectoris, ACS: acute coronary syndrome, iCMP: ischaemic cardiomyopathy;

A significant difference was found between sex and age and frequency of CHD $\left(\chi^{2}=11.989, p=0.007\right)$. In the age below 65 , a significantly higher percentage of men than women suffered from CHD (Figure 3).

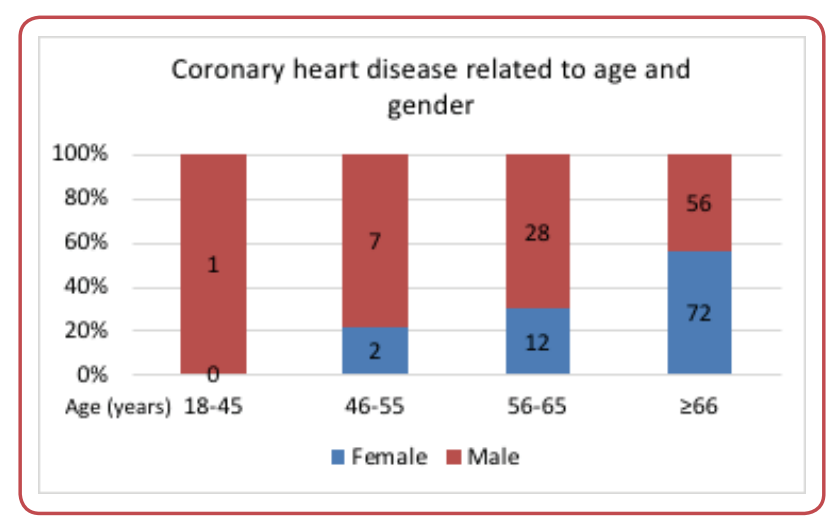

Figure 3: Incidence of ischaemic heart disease in relation to the sex and age of the patient

No significant difference was found between individual types of CHD and patients' age $\left(\chi^{2}=\right.$ $8.791, \mathrm{p}=0.186$ ), a positive family history of cardiovascular disease $\left(\chi^{2}=0.429, \mathrm{p}=0.807\right)$ or a cigarette smoking $\left(\chi^{2}=0.465, p=0.793\right)$.

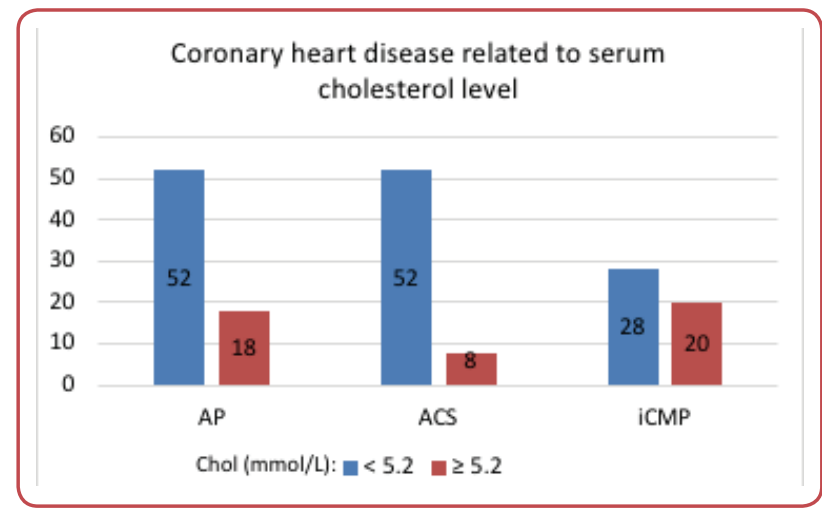

Figure 4: Distribution of ischaemic heart disease in relation to serum cholesterol values

*AP: angina pectoris, ACS: acute coronary syndrome, iCMP: ischaemic cardiomyopathy, Chol: cholesterol;
A significant difference was found between certain types of CHD and cholesterol values $\left(\chi^{2}=\right.$ $14.980, p=0.001$ ). In patients diagnosed with AP, $23.5 \%$ of those with normal cholesterol were found, $13.3 \%$ were diagnosed with ACS and $45.8 \%$ were diagnosed with iCMP (Figure 4).

A significant difference was found between certain types of CHD and the presence of diabetes $\left(\chi^{2}=\right.$ 9.148, $p=0.010$ ). Patients diagnosed with ACS in $43.3 \%$ of cases also had diabetes mellitus, in contrast to patients diagnosed with AP and iCMP where diabetes as a risk factor was present in a significantly lower percentage (Figure 5).

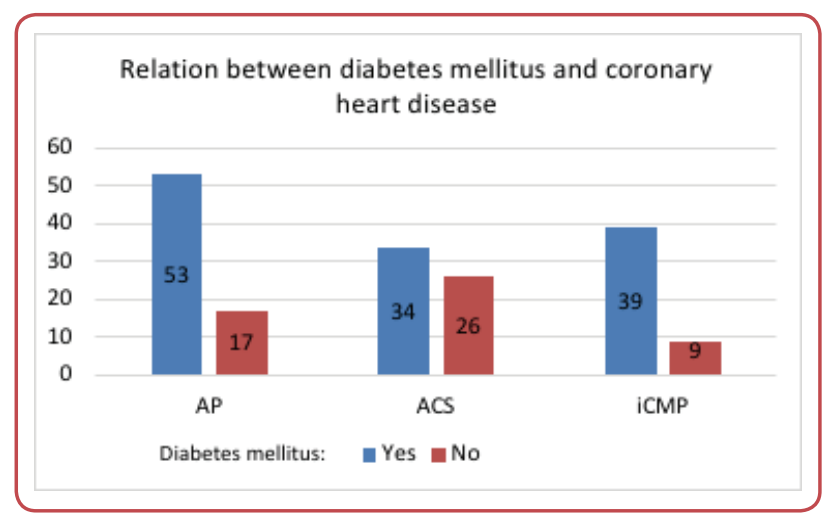

Figure 5: Distribution of ischaemic heart disease in relation to whether the patient suffered from diabetes mellitus

${ }^{\star} A P$ : angina pectoris, ACS: acute coronary syndrome, iCMP: ischaemic cardiomyopathy;

No statistically significant difference was found either between individual types of CHD and hypertension $\left(\chi^{2}=4.821, p=0.090\right)$, or between certain types of CHD and BMI $\left(\chi^{2}=2.312, p=0.315\right)$.

\section{Discussion}

The decline in standardised CVD mortality was observed in many European countries between the 1970s and 1990s including the most prompt and significant decline in wealthier countries, reflecting the potential for prevention of premature death and prolongation of healthy years of life. Mortality remains high in several Eastern European countries. ${ }^{23}$

CVDs are the leading cause of death in the Republic of Srpska. In the observed period from 20072011, the percentage of CVD in total mortality is constantly increasing (from $50.17 \%$ in 2007 to $53.73 \%$ in 2011). ${ }^{7}$ During 2013 and 2014, there is a declining trend in CVD mortality. In the Re- 
public of Srpska the CVDs cause $47.3 \%$ of total mortality. ${ }^{24}$

The research data show that up to the age of 65 , CHD affected a significantly higher percentage of men than women. This is explained by the protective effect of the female sex hormones on the occurrence of atherosclerotic heart disease. Similar results were obtained by other authors in their research. ${ }^{25}$ In the study published in 2015, Mozaffarian et al showed that up to the age of 65 there is a significantly higher number of men than women suffering from heart attack and fatal cardiovascular disease, with the subsequently declining difference and with much higher number of women older than 85 being affected. Also they demonstrated a significantly higher percentage of women suffering from stable AP and men with myocardial infarction in all age groups. ${ }^{26}$ Similar results were obtained in this study.

European Action on Secondary and Primary Prevention to Reduce Events resulted in three big studies: EUROASPIRE I, II and III. ${ }^{27-29}$ The objective of these studies was to determine the prevalence of risk factors in coronary patients, ie how much changing lifestyle habits and educational programs are able to reduce risk factors and achieve target values according to the guidelines for cardiovascular prevention of the European Society of Cardiology. The set targets were related to smoking cessation, healthier diet, adequate physical activity, achieving BMI lower than 25 $\mathrm{kg} / \mathrm{m}^{2}$, blood pressure lower than 140/90 $\mathrm{mmHg}$, total cholesterol lower than $5 \mathrm{mmol} / \mathrm{L}$, LDL-cholesterol lower than $3 \mathrm{mmol} / \mathrm{L}) .{ }^{27,28}$ Following the implementation of the 2012 European recommendations for the prevention of coronary heart disease, EUROASPIRE IV was organised in 24 European countries during 2012 and 2013. ${ }^{23,30}$ Between EUROASPIRE I (1996) and EUROASPIRE IV (2013), it was observed that the proportion of smokers did not change and that blood pressure control did not improve despite increased use of antihypertensive drugs, while the number of patients with (central) obesity continued to increase. On the other hand, lipid status control has improved significantly. ${ }^{29,31,32}$

The trend of incidence of risk factors for CHD in the Study of monitoring coronary patients in the Republic of Srpska (ROSCOPS) was made according to the EUROASPIRE methodology. The ROSCOPS I study was conducted in 1999-2001 in 5 centres and included 430 patients. The data indi- cate a high prevalence of modifiable risk factors: there were $40.5 \%$ smokers, $74.3 \%$ hypertensive patients, $28.4 \%$ patients with hyperlipidaemia, $24.3 \%$ with diabetes, $25.7 \%$ with obesity. After two years, the follow-up study of coronary patients ROSCOPS II (2002-2003), ROSCOPS III during 2006-2007, ROSCOPS IV during 2012 and ROSCOPS V during 2016 continues, which still show a high percentage of modifiable risk factors. The increase in obese patients and patients with elevated cholesterol levels is worrying. ${ }^{33,34}$

Data from this study shown that the leading risk factor were hypertension (88.8\%), followed by hypercholesterolaemia with $73.9 \%$, obesity $71 \%$ and positive family history in $63.8 \%$ of patients, while $29.2 \%$ of patients were diagnosed with diabetes mellitus and the proportion of smokers was $24.1 \%$ of the total number of patients. Compared to the research conducted in Croatia in the period 2007-2010 in hospitalised CHD patients, risk factors have a similar prevalence, except for smoking which in this sample showed a lower prevalence ( $24.1 \%$ vs $42.2 \%$ ). The reason for the lower prevalence of smoking in this study is the assumption that a certain number of non-smokers are actually ex-smokers who stopped smoking after the illness, while in the Croatian study the data were taken during the patient's hospitalisation, ie at the time of coronary events. ${ }^{30}$

The main and independent risk factors for cardiovascular disease are cigarette smoking to any extent, high blood pressure, elevated total cholesterol and LDL-cholesterol, low HDL-cholesterol, diabetes and advanced age. The quantitative relationship between the listed risk factors and their influence on the development of cardiovascular diseases is shown by numerous studies (eg Framingham Heart Study). ${ }^{35}$ The studies show that the main risk factors have an augmentative effect on the occurrence of cardiovascular diseases. Therefore, a person's overall risk of becoming ill can be estimated by multiplying the risk posed by each of the major risk factors individually. ${ }^{36}$

Tobacco smoking as an independent risk factor may result in a sevenfold increase in the risk of CHD. ${ }^{15}$ The harmful effects of tobacco are proportional to the length of smoking and the amount of cigarettes smoked. On average, smokers die three years earlier than non-smokers, and with other risk factors combined, dying can be 10-15 years premature. The effect of tobacco smoking is especially pronounced if smoking is started before 
the age of fifteen. Studies show that three years after smoking cessation, the risk of CHD equals the risk of non-smokers. ${ }^{37}$ Thus, in EUROASPIRE IV the number of smokers at the time of the interview was $16 \%$, in ROSCOPS V $21 \%$ (the interview was conducted at least 6 months after the coronary incident), while the number of smokers at the time of the coronary incident was much higher ( $48.6 \%$ and $52 \%$, respectively). The number of smokers in this study was $24.1 \%$, assuming that the number of smokers at the time of the coronary incident was much higher.

High blood pressure is the so-called major risk factor for AP. ${ }^{38}$ The prevalence of arterial hypertension increases with age. In addition to genetic factors, hypertension can be caused by obesity, alcohol consumption, intake of higher amounts of salt and animal fats and other factors.

Dyslipoproteinaemia represents an equally important and independent risk factor for the development and progression of the atherosclerotic process. This is especially true for the relation between LDL cholesterol increase and the HDL cholesterol concentration decrease and the increase in CHD incidence. ${ }^{39}$ With a moderate increase in LDL cholesterol, in the presence of other risk factors such as smoking, hypertension or diabetes, the adverse effect of LDL on the progression of the atherosclerotic process is significantly increased. Patients with diabetes mellitus often have hypercholesterolaemia, ie increased amount of especially atherogenic LDLs. Their mortality from coronary heart disease is almost 10 times higher than in people without overt diabetes. ${ }^{40}$

Diabetes mellitus and CHD are strongly associated. Diabetes is associated with various forms of CHD, especially in women. Almost half of diabetics die from heart disease. Only a decrease in glucose tolerance poses a risk of developing coronary heart disease. Mortality from coronary heart disease in insulin-dependent diabetics is almost 10 times higher than in people without diabetes. ${ }^{41}$ Comparison of the results with European and national data shows a significantly higher prevalence of elevated cholesterol, obesity, hypertension and smoking in the examined sample. The prevalence of diabetes in this sample is higher compared to EUROASPIRE IV, but slightly lower compared to the national population.

The results of this study show a high prevalence of variable risk factors, so it is obvious that phy- sicians should insist on promoting a healthy lifestyle and improving patient awareness. It is necessary to raise the awareness of the general public about the need and importance of a healthier lifestyle and the preservation and improvement of health. Cooperation between all levels of health care in preventing and combating risk factors should be improved.

\section{Conclusion}

The results of this study show a high prevalence of preventable risk factors for CVD. Of particular importance is the timely detection and treatment of risk factors by family physicians and strengthening the personal responsibility of each individual in choosing their lifestyle and active involvement in the therapeutic process.

\section{Acknowledgements}

None.

\section{Conflict of interest}

None.

\section{References}

1. Jensen RV, Hjortbak MV, Bøtker HE. Ischemic heart disease: an update. Semin Nucl Med 2020 May;50(3):195207.

2. Maksimović ŽM, Banjac N, Čović M. Significance of dyspnoea as a symptom in the emergency department of the primary healthcare centre. Scr Med 2020;51(3):158-65.

3. Frostegård J. Immunity, atherosclerosis and cardiovascular disease. BMC Med 2013 May 1;11:117. doi: 10.1186/1741-7015-11-117.

4. WHO. Health topics: cardiovascular diseases [Internet]. Geneva. Available from: https://www.who.int/ health-topics/cardiovascular-diseases/. [Cited: 2021July-7].

5. Hartley A, Marshall DC, Salciccioli JD, Sikkel MB, Maruthappu M, Shalhoub J. Trends in mortality from ischemic heart disease and cerebrovascular disease in Europe: 1980 to 2009. Circulation 2016;133(20):191626. 
6. Kralj V, Brkić Biloš I. Morbidity and mortality from cardiovascular diseases. Cardiol Croat 2013;8(1011):373-8.

7. Townsend N, Wilson L, Bhatnagar P, Wickramasinghe K, Rayner M, Nichols M. Cardiovascular disease in Europe: epidemiological update 2016. Eur Heart J 2016;37(42):3232-45.

8. Mihajlović D, Maksimović ŽM, Dojčinović B, Banjac N. Acute coronary syndrome (STEMI, NSTEMI and unstable angina pectoris) and risk factors, similarities and differences. Scr Med 2020;51(4):252-60.

9. Collet JP, Thiele H, Barbato E, Barthélémy O, Bauersachs J, Bhatt DL, et al; ESC Scientific Document Group. 2020 ESC Guidelines for the management of acute coronary syndromes in patients presenting without persistent ST-segment elevation. Rev Esp Cardiol (Engl Ed) 2021 Jun;74(6):544. doi: 10.1016/j.rec.2021.05.002.

10. Lemic-Stojcevic N, Dundas R, Jenkins S, Rudd A, Wolfe C. Preventable risk factors for coronary heart disease and stroke amongst ethnic groups in London. Ethn Health 2001 May;6(2):87-94.

11. Wu CY, Hu HY, Chou YJ, Huang N, Chou YC, Li CP. High blood pressure and all-cause and cardiovascular disease mortalities in community-dwelling older adults. Medicine (Baltimore) 2015 Nov;94(47):e2160. doi: 10.1097/MD.0000000000002160.

12. Carbone S, Canada JM, Billingsley HE, Siddiqui MS, Elagizi A, Lavie CJ. Obesity paradox in cardiovascular disease: where do we stand? Vasc Health Risk Manag 2019 May 1;15:89-100.

13. Peters SA, Singhateh Y, Mackay D, Huxley RR, Woodward M. Total cholesterol as a risk factor for coronary heart disease and stroke in women compared with men: A systematic review and meta-analysis. Atherosclerosis 2016 May;248:123-31.

14. Leon BM, Maddox TM. Diabetes and cardiovascular disease: Epidemiology, biological mechanisms, treatment recommendations and future research. World J Diabetes 2015 Oct 10;6(13):1246-58.

15. Gallucci G, Tartarone A, Lerose R, Lalinga AV, Capobianco AM. Cardiovascular risk of smoking and benefits of smoking cessation. J Thorac Dis 2020 Jul;12(7):386676.

16. Li J, Siegrist J. Physical activity and risk of cardiovascular disease - a meta-analysis of prospective cohort studies. Int J Environ Res Public Health 2012 Feb;9(2):391-407.

17. Maas AH, Appelman YE. Gender differences in coronary heart disease. Neth Heart J 2010 Dec;18(12):598-602.

18. Dhingra R, Vasan RS. Age as a risk factor. Med Clin North Am 2012 Jan;96(1):87-91.

19. Jokšić R, Cvetićanin B, Lekin I, Jokšić M. Chest pain: A significant guideline in the diagnosis of acute coronary syndrome. ABC 2011;11(1):12-7.

20. Ibanez B, James S, Agewall S, Antunes MJ, Bucciarelli-Ducci C, Bueno H, et al. 2017 ESC Guidelines for the management of acute myocardial infarction in patients presenting with ST-segment elevation: The Task Force for the Management of Acute Myocardial Infarction in Patients Presenting With ST-segment Elevation of the European Society of Cardiology (ESC). Eur Heart J 2018 Jan 7;39(2):119-77.

21. Nolan JP, Soar J, Zideman DA, Biarent D, Bossaert LL,
Deakin C, et al; ERC Guidelines Writing Group. European Resuscitation Council Guidelines for Resuscitation 2010 Section 1. Executive summary. Resuscitation 2010 Oct;81(10):1219-76.

22. WHO. Consultation on Obesity [Internet]. Geneva; 1997. Available from: https://www.who.int/newsroom/fact-sheets/detail/obesity-and-overweight/. [Cited: 2021-July-7].

23. Perk J, De Backer G, Gohlke H, Graham I, Reiner Z, Verschuren M, et al; European Association for Cardiovascular Prevention \& Rehabilitation (EACPR); ESC Committee for Practice Guidelines (CPG). European Guidelines on cardiovascular disease prevention in clinical practice (version 2012). The Fifth Joint Task Force of the European Society of Cardiology and Other Societies on Cardiovascular Disease Prevention in Clinical Practice (constituted by representatives of nine societies and by invited experts). Eur Heart J 2012 Jul;33(13):1635-701.

24. Štrbac S, Pilipović Broćeta N, Todorović N, Vujić Aleksić V, Stević S, Lolić A, et al. Short-term training of family medicine teams on cardiovascular risk assessment and management - effects on practice and outcomes. Scr Med 2021 Sep;52(3):165-73.

25. Regitz-Zagrosek V, OerteltPrigione $S$, Prescott E, Franconi F, Gerdts E, Foryst-Ludwig A, et al; EUGenMed Cardiovascular Clinical Study Group. Gender in cardiovascular diseases: impact on clinical manifestations, management, and outcomes. Eur Heart J 2016;37(1):24-34.

26. Mozaffarian D, Benjamin EJ, Go AS, Arnett DK, Blaha MJ, Cushman M, et al; American Heart Association Statistics Committee and Stroke Statistics Subcommittee. Heart disease and stroke statistics--2015 update: a report from the American Heart Association. Circulation 2015 Jan 27;131(4):e29-322.

27. EUROASPIRE II Study Group. Lifestyle and risk factor management and use of drug therapies in coronary patients from 15 countries; principal results from EUROASPIRE II Euro Heart Survey Programme. Eur Heart J 2001 Apr;22(7):554-72.

28. EUROASPIRE I and II Group; European Action on Secondary Prevention by Intervention to Reduce Events. Clinical reality of coronary prevention guidelines: a comparison of EUROASPIRE I and II in nine countries. EUROASPIRE I and II Group. European Action on Secondary Prevention by Intervention to Reduce Events. Lancet 2001 Mar 31;357(9261):995-1001.

29. Graham I, Atar D, Borch-Johnsen K, Boysen G, Burell G, Cifkova R, et al; European Society of Cardiology (ESC) Committee for Practice Guidelines (CPG). European guidelines on cardiovascular disease prevention in clinical practice: executive summary: Fourth Joint Task Force of the European Society of Cardiology and Other Societies on Cardiovascular Disease Prevention in Clinical Practice (Constituted by representatives of nine societies and by invited experts). Eur Heart J 2007 Oct;28(19):2375-414.

30. Bergovec M, Reiner Ž, Miličić D, Vražić H. Differences in risk factors for coronary heart disease in patients from continental and Mediterranean regions of Croatia. Wien Klin Wochenschr 2008;120:684-92.

31. Kotseva K, Wood D, De Bacquer D, De Backer G, Rydén 
L, Jennings C, et al; EUROASPIRE Investigators. EUROASPIRE IV: A European Society of Cardiology survey on the lifestyle, risk factor and therapeutic management of coronary patients from 24 European countries. Eur J Prev Cardiol 2016 Apr;23(6):636-48.

32. EUROASPIRE II Study Group. Lifestyle and risk factor management and use of drug therapies in coronary patients from 15 countries; principal results from EUROASPIRE II Euro Heart Survey Programme. Eur Heart J 2001 Apr;22(7):554-72.

33. Vulić D, Krneta M, Lazarević A, Ciric Z. [Results of monitoring risk factors and therapeutic approach in a study of monitoring coronary patients in the Republic of Srpska (ROSCOPS I i II)]. Balneoklimatologija 2005;29(1):385-9. Serbian.

34. Vulić D, Krneta M, Šobot M. [Guidelines of secondary prevention coronary artery disease prevention]. Srce i krvni sudovi 2011;30(4):241-5. Serbian.

35. Scottish Intercollegiate Guidelines Network (SIGN) [Internet]. Acute coronary syndromes. Edinburgh: SIGN; 2013. [Cited: 2020-July-7]. Available from: http:// www.sign.ac.uk.

36. Grundy SM, Pasternak R, Greenland P, Smith S Jr, Fuster $\mathrm{V}$. Assessment of cardiovascular risk by use of multiple-risk-factor assessment equations: a statement for healthcare professionals from the American Heart Association and the American College of Cardiology. Circulation 1999 Sep 28;100(13):1481-92.

37. Villablanca AC, McDonald JM, Rutledge JC. Smoking and cardiovascular disease. Clin Chest Med 2000 Mar;21(1):159-72.

38. Richardson PJ, Hill LS. Relationship between hypertension and angina pectoris. Br J Clin Pharmacol 1979;7 Suppl 2(Suppl 2):249S-253S. doi: 10.1111/j.13652125.1979.tb04697.x.

39. Gidding SS, Allen NB. Cholesterol and atherosclerotic cardiovascular disease: a lifelong problem. J Am Heart Assoc 2019 Jun 4;8(11):e012924. doi: 10.1161/ JAHA.119.012924.

40. Howard BV, Robbins DC, Sievers ML, Lee ET, Rhoades D, Devereux RB, et al. LDL cholesterol as a strong predictor of coronary heart disease in diabetic individuals with insulin resistance and low LDL: The Strong Heart Study. Arterioscler Thromb Vasc Biol 2000 Mar;20(3):830-5.

41. Ličina M, Potpara T, Polovina M, Ostojić M, Milić N, Giga $\mathrm{V}$, et al. [Regulation of risk factors in patients with ischemic heart disease treated with percutaneous coronary intervention]. Srce i krvni sudovi 2011;11(1):25763. Serbian. 